\title{
Phenotypic and Genotypic Diversity of Rhizobia Nodulating Faba Bean from Various Egyptian Locations
}

Omar A Hewedy*, Ragaa A Eissa, Elzanaty AM, Nagaty HH and Abd Elbary MI

Genetics Department, Faculty of Agriculture, Minoufiya University, Shibin El-Kom, Egypt

\begin{abstract}
Thirteen Rhizobial isolates from root nodules of Faba beans (Vicia faba L.) were obtained from eleven governorates, representing different agro-ecological, agro-climatic and soil conditions in Egypt. A polyphasic approach, including phenotypic and genotypic techniques were used to study their diversity. Rhizobium isolates were examined for their ability to tolerate salt stress and antibiotic resistance. We used four $\mathrm{NaCl}$ concentrations ranging from $0.1 \%, 1 \%, 3 \%$ and $5 \%$ in liquid media and plates, moreover we used 24 different antibiotic disks to determine resistance or sensitive among the tested isolates on plates. The obtained results after salt tolerance and antibiotic response of the R. leguminosarium strains showed that the isolate No. RL9 was the superior strain for salt tolerance. The following strains for salt tolerance were the isolates (RL4) and (RL12), although the isolate No. RL11 was the superior strain for antibiotic resistant then isolates No. RL 13 and Rh3. Growth of all isolates were inhibited above $3 \% \mathrm{NaCl}$ except five isolates RL4, RL9, RL10, $\mathrm{RL} 12$ and $\mathrm{RL} 13$. Also the antibiotic resistance of the isolated strains showed a high level of resistance against Cefoxitin $\left(\mathrm{FOX}_{30}\right)$ and Cefuroxime $\left(\mathrm{Cxm}_{30}\right)$. The genetic diversity was studied using RAPD-PCR technique and we used specific primer (nodC) amplification. In this study we found that $\mathrm{OPE}_{15}$ and $\mathrm{OPG}_{04}$ primers showed the highest polymorphism level among the tested isolates, however $\mathrm{OPJ}_{20}$ and $\mathrm{OPC}_{06}$ primers showed the lowest polymorphism level.
\end{abstract}

Keywords: Faba bean; Antibiotic resistance; Salt tolerance; RAPDPCR; nodC

\section{Introduction}

Faba bean (Vicia faba L.) is a major leguminous crop grown worldwide, it is most intensively cultivated in the Middle East and in North East Africa [1]. Rhizobium leguminosarium symbiovar. Vicia forms a nitrogen-fixing root nodule symbiosis with faba bean $[2,3]$. Since Faba bean has been grown for centuries in Egypt, it was of interest to determine the diversity of rhizobia forming nitrogenfixing nodules with this important legume crop. The soils used in our studies distributed in geographically different locations in Egypt. Rhizobia are soil bacteria which are capable of forming nitrogen-fixing nodules with different leguminous plants and have a significant role in nutrient cycling due to biological nitrogen fixation and enhancing crop productivity [4]. The symbiotic relationships between rhizobia and leguminous plants provide soil with nitrogen. Many studies have addressed the diversity level of $V$. faba rhizobia; mainly focusing on rhizobial populations from the same location [5] or for comparison with Rhizobium leguminosarum isolates from other legume species [6]. The diversity of rhizobia provides valuable bio resource for the search of bacterial isolates in attempt to find isolates that maximize nitrogen fixation, and hence increase legume crop productivity [7]. Salinity stress is one of the most serious factors limiting the productivity of agriculture. High salt can directly impair rhizobialegume early interactions during nodule formation [8]. In general, Egypt suffering from increasing population in both drought and arid climate. The symbiotic interaction between rhizobia and legumes is initiated by an exchange of complex molecular signals that confer hostspecificity. Rhizobia respond to these by one or more of the constitutive nod $\mathrm{D}$ genes encoding for a soluble cytoplasmatic protein activating the other nod genes when they interact with the appropriate plant signal compounds. This leads to the biosynthetic enzymes of lipochitin oligosaccharides (Nod Factors) encoded by nod ABC genes. Laguerre et al., [9] used the nod $C$ gene, a common nod gene essential for nodulation in all rhizobial species, to characterize a collection of 83 rhizobial strains which represented 23 recognized species distributed in the genera Rhizobium, Sinorhizobium, Mesorhizobium and Bradyrhizobium. Many techniques were developed and widely used to detect polymorphisms in many organisms including bacteria. Among these techniques, RAPD technique is a polymerase chain reaction (PCR) to detect the polymorphisms in genomic DNA [10]. Genomic DNA Fingerprinting using random amplification of polymorphic DNA (RAPD) has been found to be useful in differentiating between Rhizobial strains. [11] proposed this method for identification and phylogenetic grouping of Rhizobium isolates. RAPD PCR technique provides reliable information on the diversity of Rhizobium populations in soils [12].

The objectives of this study are to isolate salt tolerant Rhizobium and investigate the effects of antibiotics and $\mathrm{NaCl}$ on growth of isolates. Furthermore detect the diversity of these isolates by using RAPD.

\section{Material and Methods}

\section{Isolation of Rhizobia from nodules}

Thirteen Rhizobial isolates isolated from the root nodules of Faba bean (Vicia faba L.) isolates were obtained from eleven governorates as presented in (Table 1). All nodules were cut off in a laminar flow cabinet with small pieces of root and washed thoroughly with $2.5 \% \mathrm{NaOCl}$ and sterile water. Nodules were surface sterilized with $70 \%$ ethanol

*Corresponding author: Omar A Hewedy, Genetics Department, Faculty of Agriculture, Minoufiya University, Shibin El-Kom, Egypt, Tel: 00201223570768 E-mail: hewedy.omar@gmail.com

Received June 23, 2014; Accepted July 21, 2014; Published July 30, 2014

Citation: Hewedy OA, Eissa RA, Elzanaty AM, Nagaty HH, Abd Elbary MI (2014) Phenotypic and Genotypic Diversity of Rhizobia Nodulating Faba Bean from Various Egyptian Locations. J Bioprocess Biotech 4: 170 doi: 10.4172/21559821.1000170

Copyright: (c) 2014 Hewedy OA, et al. This is an open-access article distributed under the terms of the Creative Commons Attribution License, which permits unrestricted use, distribution, and reproduction in any medium, provided the original author and source are credited. 


\begin{tabular}{|c|c|c|c|c|}
\hline Isolates & Nitrogenase Activity & Nodules No. & Shoot Dry (g) & Shoot Fresh (g) \\
\hline 1 & 1.60 & 23.0 & 2.10 & 13.70 \\
\hline 2 & 0.80 & 14.7 & 1.30 & 11.30 \\
\hline 3 & 1.35 & 17.3 & 3.00 & 12.50 \\
\hline 4 & 1.75 & 23.0 & 4.60 & 19.90 \\
\hline 5 & 1.00 & 18.7 & 2.00 & 12.70 \\
\hline 6 & 0.75 & 24.3 & 26.01 & 14.60 \\
\hline 7 & 2.15 & 24.3 & 1.00 & 11.10 \\
\hline 8 & 0.50 & 15.3 & 2.60 & 16.50 \\
\hline 9 & 3.30 & 32.3 & 8.80 & 29.00 \\
\hline 10 & 2.00 & 22.7 & 5.00 & 24.60 \\
\hline 11 & 2.50 & 28.3 & 4.10 & 24.70 \\
\hline 12 & 2.70 & 25.3 & 6.90 & 26.10 \\
\hline 13 & 3.10 & 30.7 & 7.50 & 27.60 \\
\hline
\end{tabular}

Table 1: Locations of isolates measured for each isolate.

alcohol for $5 \mathrm{~min}$ and exhaustively washed in sterile distilled water. After washing the root nodules were taken from the roots with care not to damage the surface, washed thoroughly in distilled water. Nodules were then transferred to $0.2 \%(\mathrm{~W} / \mathrm{V})$ solution of mercuric chloride for 3-5 minutes. Each nodule was crushed under aseptic conditions and streaked onto a Yeast-Mannitol Agar plate (YMA) using a sterile loop and incubated at $28^{\circ} \mathrm{C}$. Single colonies were picked up from the original streaked plates. Pure cultures of Rhizobium leguminosarum were isolated according to Vincent methods and retreated on YMA containing Congo red to ensure purity before storage in $20 \%$ glycerol at $-20^{\circ} \mathrm{C}$. Stock cultures of the Rhizobium isolates were maintained on slants of YEM at $4^{\circ} \mathrm{C}$ and refreshed periodically.

\section{Phenotypic characterization of isolates}

Antibiotic resistance pattern: All isolates were evaluated for their responses as resistant or sensitive against 24 different antibiotic disks as shown in Table 2.

Rhizobium isolates were tested on YMA agar supplemented with following antibiotic disks that presented in Table 2 according to Eaglesham's technique [13]. This was done as the following each isolate plated on YEM plates and the antibiotic disks were distributed on the surface of the plate. The plates were incubated for 3 days at $28^{\circ} \mathrm{C}$. After this period the presence or absence of an inhibition zone around antibiotic disks was recorded, indicating sensitivity or resistance, respectively.

Effect of Salinity on tested Rhizobium isolates:

- YEMA: The ability of the Rhizobial isolates to grow in various concentration of $\mathrm{NaCl}$ was tested by plating them on YEM agar Petri dishes. YEMA was prepared with different concentrations of $\mathrm{NaCl}$ ranging from $(0.1 \%, 1 \%, 3 \%$ and $5 \% \mathrm{wt} / \mathrm{vol}) \mathrm{NaCl}$. All the plates were incubated at $28^{\circ} \mathrm{C}$ for three days in triplicate in addition to control.

- YEM broth: Testing of salt tolerance was measured as the ability of the bacterial cells to grow and divide under the stress of used $\mathrm{NaCl}$ concentration. Test tubes $(10 \mathrm{ml})$ each containing $5 \mathrm{ml}$ YEM medium, were inoculated with a bacterial isolates and incubated at $28^{\circ} \mathrm{C}$ for 72 hours. $100 \mu \mathrm{l}$ of suspension $\left(1 \times 10^{-7} \mathrm{cfu} / \mathrm{ml}\right)$ of the grown isolate was used for the inoculation of $5 \mathrm{ml}$ YEM medium containing various $\mathrm{NaCl}$ concentration $(0.1 \%, 1 \%, 3 \%$ and $5 \%$ wt/ vol) and the test tubes were incubated at $28^{\circ} \mathrm{C}$ for different time ranging from zero time, $12,24,36,48,60$ and $72 \mathrm{~h}$ of incubation and the growth rate in Rhizobial isolates tested using optical density
(OD) at three replicates. The turbidity was measured using Jenway UV-VIS. spectrophotometer model UV-6305 at $600 \mathrm{~nm}$ against the blank (sterilized uninoculated YEM broth) (Table 4).

\section{DNA isolation}

Total genomic DNA of each isolate was extracted from bacterial cultures grown in yeast extract mannitol media (YEM) according to Ausubel et al., [14] method and kept at $-20^{\circ} \mathrm{C}$. The cells were lysed with sodium dodecyl sulphate (SDS), protein-lipopolysaccharides complexes were removed by using cetyl tri methyl ammonium bromide (CTAB), and DNA was precipitated from solution using isopropanol.

\section{RAPD-PCR reaction and amplification}

\section{Oligonucleotide sequences of the random primers:}

\section{OPE20---5'AACGGTGACC 3'---OPA04---5'AATCGGGCTG 3' \\ OPJ20---5'AAGCGGCCTC 3'---OPE 15---5'AACGGTGACC 3'}

\section{OPG 04---5'AGCGTGTCTG 3'---OPC 06---5'GAACGGACTC 3'}

Total genomic DNA was extracted from exponentially grown cultures and PCR reactions were carried out using an arbitrary primer RAPD-PCR were used in this study RAPD-PCR was performed in the total volume of $25 \mu \mathrm{l}$ of reaction mixture containing $1 \mu \mathrm{l}$ of DNA template, $1 \mu \mathrm{l}$ dNTPs mix, $4 \mu \mathrm{l}(10 \mathrm{pmol})$ of an arbitary primer and $1 \mu \mathrm{l}$ of Taq polymerase with $2.5 \mu \mathrm{l}$ Taq buffer and $15.5 \mu \mathrm{l}$ sterilized water.

PCR conditions were as follows template DNA was denatured at $94^{\circ} \mathrm{C}$ for 4 min then the PCR was carried out for 35 cycles $(1 \mathrm{~min}$ at $94^{\circ} \mathrm{C}, 1 \mathrm{~min}$ at $34^{\circ} \mathrm{C}, 2 \mathrm{~min}$ at $72^{\circ} \mathrm{C}$, for each cycle). Finally, a $7 \mathrm{~min}$ extension period at $72^{\circ} \mathrm{C}$ was performed. Amplified products were resolved on a $1 \%(\mathrm{w} / \mathrm{v})$ Agarose-TBE gel electrophoresis and separated by running $5 \mu$ of PCR reaction mixture at $100 \mathrm{~V}$ for $1 \mathrm{~h}$ and stained

\begin{tabular}{|c|c|c|}
\hline No. & Disks & Name \\
\hline 1 & AK30 & Amikacin \\
\hline 2 & AM 10 & Ampicilin \\
\hline 3 & ATM 10 & Aztreonam \\
\hline 4 & B 0.04 & Bacitracin \\
\hline 5 & C 30 & Chloramphenicol \\
\hline 6 & CIP5 & Ciprofloxacin \\
\hline 7 & CLR 15 & Cefuroxime sodium \\
\hline 8 & CN 10 & Gentamicin \\
\hline 9 & CRO 30 & Ceftriaxone \\
\hline 10 & Cxm30 & Cefuroxime sodium \\
\hline 11 & E 15 & Erythromycin \\
\hline 12 & FOX 30 & Cefoxitin \\
\hline 13 & IPM 10 & Imipenem \\
\hline 14 & K 30 & Kanamycin \\
\hline 15 & MA 30 & Cefamandole \\
\hline 16 & Mem 10 & Meropenem \\
\hline 17 & N 30 & Neomycin \\
\hline 18 & NOR10 & Norfloxacin \\
\hline 19 & OX 1 & Dloxaciolin \\
\hline 20 & S 10 & Streptomycin \\
\hline 21 & Sam 20 & Sulbactampicillin \\
\hline 22 & SXT25 & Sulphamethoxazole \\
\hline 23 & T 30 & Tetracycline \\
\hline 24 & VA 30 & Vancomycin \\
\hline
\end{tabular}

Table 2: Antibiotic disks used in this study. 


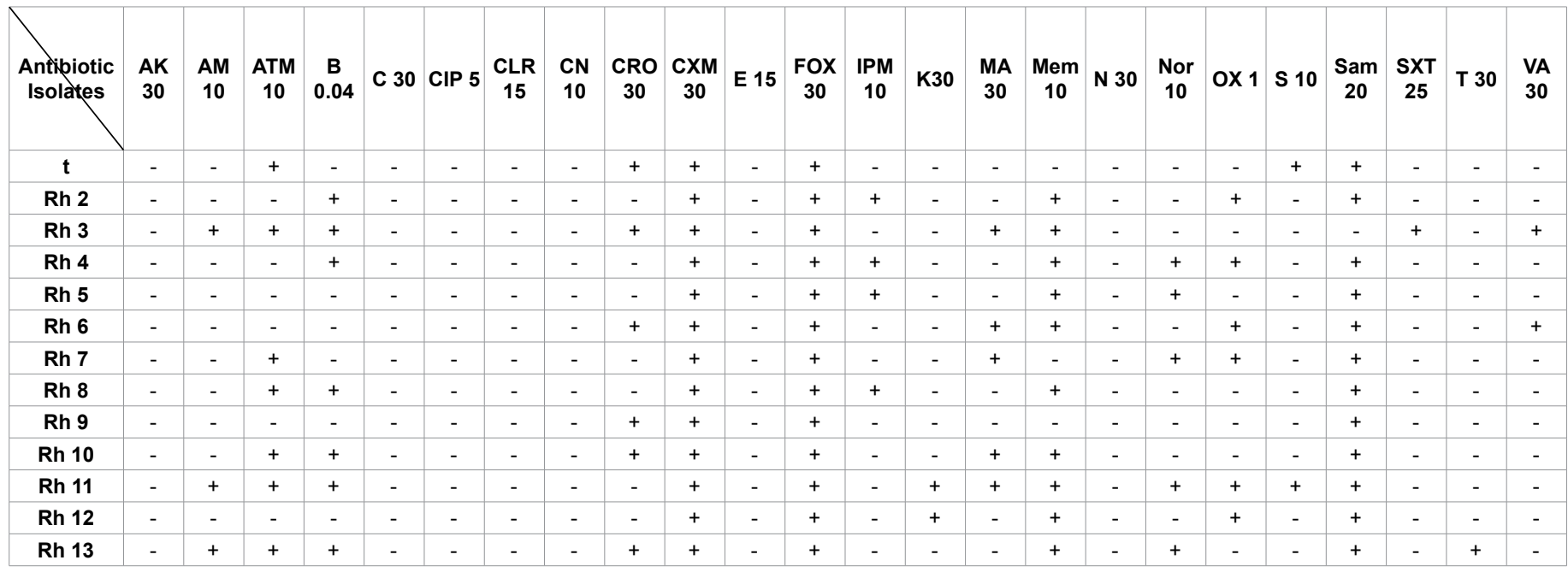

Table 3: Response of Rhizobium isolates to 24 different types of antibiotic disks

\begin{tabular}{|c|c|c|c|c|c|c|c|c|c|c|c|c|c|}
\hline Isolates & Rhl & Rh2 & Rh3 & Rh4 & Rh5 & Rh6 & Rh7 & RhS & Rh9 & RhI 0 & Rh11 & Rh12 & Rh13 \\
\hline Rhl & 1 & & & & & & & & & & & & \\
\hline Rh2 & 0.3 & 1 & & & & & & & & & & & \\
\hline Rh3 & 0.33 & 0.3 & 1 & & & & & & & & & & \\
\hline Rh4 & 0.27 & 0.87 & 0.28 & 1 & & & & & & & & & \\
\hline Rh5 & 0.33 & 0.62 & 0.23 & 0.75 & 1 & & & & & & & & \\
\hline Rh6 & 0.4 & 0.5 & 0.5 & 0.45 & 0.4 & 1 & & & & & & & \\
\hline Rh7 & 0.44 & 0.4 & 0.31 & 0.5 & 0.44 & 0.5 & 1 & & & & & & \\
\hline Rh\$ & 0.44 & 0.75 & 0.47 & 0.67 & 0.62 & 0.36 & 0.4 & 1 & & & & & \\
\hline Rh9 & 0.67 & 0.37 & 0.27 & 0.33 & 0.43 & 0.5 & 0.37 & 0.37 & 1 & & & & \\
\hline Rh10 & 0.55 & 0.5 & 0.64 & 0.45 & 0.4 & 0.6 & 0.5 & 0.67 & 0.5 & 1 & & & \\
\hline Rh11 & 0.38 & 0.46 & 0.47 & 0.54 & 0.38 & 0.43 & 0.58 & 0.46 & 0.23 & 0.58 & 1 & & \\
\hline Rh12 & 0.33 & 0.62 & 0.23 & 0.55 & 0.5 & 0.55 & 0.44 & 0.44 & 0.43 & 0.4 & 0.5 & 1 & \\
\hline Rh13 & 0.45 & 0.42 & 0.54 & 0.5 & 0.45 & 0.38 & 0.42 & 0.54 & 0.4 & 0.64 & 0.57 & 0.33 & 1 \\
\hline
\end{tabular}

Table 4: Similaritybetween different tested isolatesbased on antibiotics resistant analyses.

with ethidium bromide $(0.5 \mu \mathrm{l} / \mathrm{ml})$. The sizes of the amplified fragments were determined by comparison with $100 \mathrm{bp}$.

Plus DNA Ladder (Gene ruler) as molecular weight marker. Presence of amplified bands were observed using UV-transilluminator and the gel was photographed. Variations between amplified bands were recorded as presence or absence of DNA fragments. The dendrogram was constructed based on UPGMA cluster analysis according to dice square co-efficiant method. The dendrogram tree among the studied Rhizobium isolates based on RAPD markers were constructed using NTSYSpc version 2.1 programs depending on the similarity matrix present in Table 5.

\section{Amplification of the nodC gene}

The nodC gene from the Rhizobium isolates was amplified by PCR by using forward primer nodCf (5-GCTGCCTATGCAGACGATG-3) and reverse primer nodCr (5-GGTTACTGGCTTTCATTTGGC-3), PCRs were carried out in $50 \mathrm{ml}$ reaction mixtures [14] using the following conditions: initial denaturation at $94^{\circ} \mathrm{C}$ for $5 \mathrm{~min}$, followed by 30 cycles of $94^{\circ} \mathrm{C}$ for $1 \mathrm{~min}, 55^{\circ} \mathrm{C}$ for $1 \mathrm{~min}$, and $3 \mathrm{~min}$ at $72^{\circ} \mathrm{C}$. A final extension was done at $72^{\circ} \mathrm{C}$ for $7 \mathrm{~min}$. PCR products were separated on $2 \%$ agarose gels at $120 \mathrm{~V}$ for $1.5 \mathrm{~h}$ in TBA buffer, stained with ethidium bromide, and visualized under UV light.

Statistical analysis: Data obtained were statistically analyzed using SPSS analysis program (version 11.5). The significant differences

\begin{tabular}{|c|c|c|c|c|}
\multirow{2}{*}{ Isolate No. } & \multirow{2}{*}{ Control (0.1\%) } & \multicolumn{4}{|c|}{$\mathbf{N a C l}$ at different concentration } \\
\cline { 3 - 5 } & & $\mathbf{1 \%}$ & $\mathbf{3} \%$ & $\mathbf{5} \%$ \\
\hline 1 & 130 & 110 & 50 & 0 \\
\hline 2 & 150 & 130 & 70 & 0 \\
\hline 3 & 110 & 100 & 80 & 0 \\
\hline 4 & 140 & 120 & 90 & 50 \\
\hline 5 & 120 & 90 & 40 & 0 \\
\hline 6 & 120 & 110 & 40 & 0 \\
\hline 7 & 90 & 80 & 50 & 0 \\
\hline 8 & 100 & 80 & 60 & 0 \\
\hline 9 & 150 & 120 & 90 & 50 \\
\hline 10 & 160 & 120 & 50 & 40 \\
\hline 11 & 100 & 70 & 40 & 0 \\
\hline 12 & 140 & 110 & 90 & 60 \\
\hline 13 & 170 & 140 & 100 & 80 \\
\hline
\end{tabular}

Table 5: Response of tested isolates to different concentrations of $\mathrm{NaCl}$ on YEMA Plates $\left(1^{*} 10^{7} \mathrm{cfu} / \mathrm{ml}\right)$

among individual means were analyzed by Duncan's multiple range tests.

\section{Results and Discussion}

Faba bean has been cultivated for over 6000 years, and is grown in 57 countries worldwide. Since faba bean has been grown for centuries in Egypt, it was of interest to determine the diversity of rhizobia 
forming nitrogen-fixing symbioses with this important legume crop. The soils used in our studies differed in texture and class, and were distributed in geographically different sites in Egypt.

\section{Phenotypic characteristics}

On the basis of morphological parameters, we have confirmed differences between the isolates. Table 1 represent thirteen isolates of Rhizobium leguminosarum symbiovar Vicia isolated from nodules of Egyptian Faba beans (Vicia faba L.) collected from different geographic areas. This ten isolates were tested by Congo red technique [15], to ensure that all isolates were rhizobia and did not contaminated. These results are in agreement with those obtained by [16] they sampled two hundred and eighty seven isolates of Rhizobium in France from geographically distant field populations and characterized by their colony morphology. Rhizobial isolates were found to be microscopically similar, isolates identified as Rhizobium leguminosarium symbiovar. Vicia. According to the negative reaction to gram stain. Strains were found to be motile. On YEM agar, the growth is generally moist, whitish, smooth and gummy. The culture on YEM broth showed uniform turbidity, white sediment and need 8-10 days or longer time to attain maximal growth. These results are in agreement with those obtained by [17]. Colonies on agar after 2-3 days were large, gummy, translucent, spreading about $2-4 \mathrm{~mm}$ in diameter, similar results were reported by [18].

\section{Antibiotic resistance pattern}

Resistance to different disks of antibiotic is one of the simple and rapid methods for rhizobial isolates characterization and identification. Resistance patterns of the isolates to various antibiotics were studied to provide phenotypic data for differentiating the rhizobial isolates from each other and to determine the diversity among the isolates.
Apparently, the antibiotic resistance of the tested strains showed a high level of resistance against Cefoxitin (FOX30r) and Cefuroxime (Cxm30 r). More than $70 \%$ of the isolates showed resistance to Meropenem (Mem10r) except isolate No.1,7 and 9. Some isolates were resistant to Sulbactampicillin (Sam20r). Moreover all the isolates showed generalized sensitivity to Amikacin (AK30s), Chloramphenicol (C30s), Ciprofloxacin (CIP5s), Cefuroxime sodium (CLR15s), Gentamicin (CN10s) and Erythromycin (E15s). Furthermore all the isolates showed sensitivity to Tetracycline (T30s) except isolate No.13, The generalized sensitivity to Tetracycline in this study agrees with the results reported previously by Jordan (1984) for the genus Rhizobium and by Hagedorn [19] for R.leguminosarum sv. trifolli. Finally all the isolates showed Sensitivety to Streptomycin (S 10 s) except isolate No.1

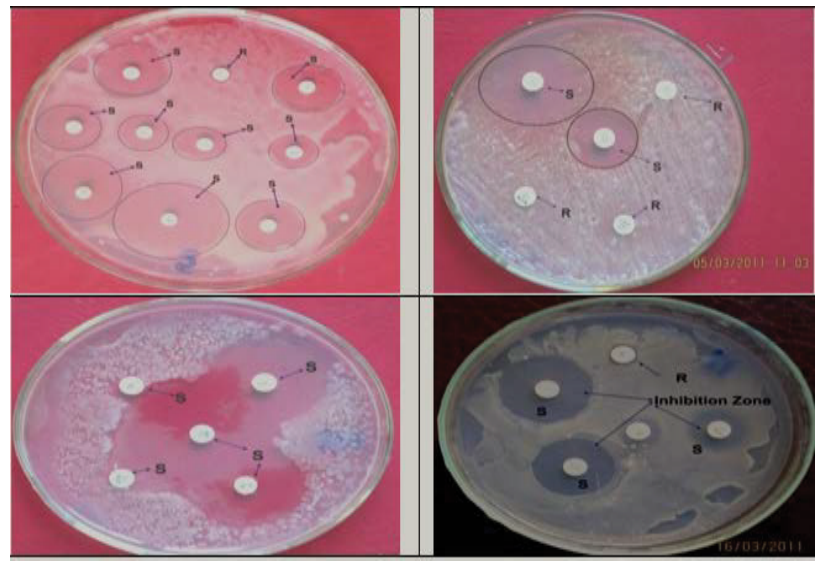

Figure 1: Response of different isolates to kinds of different antibiotic discs.

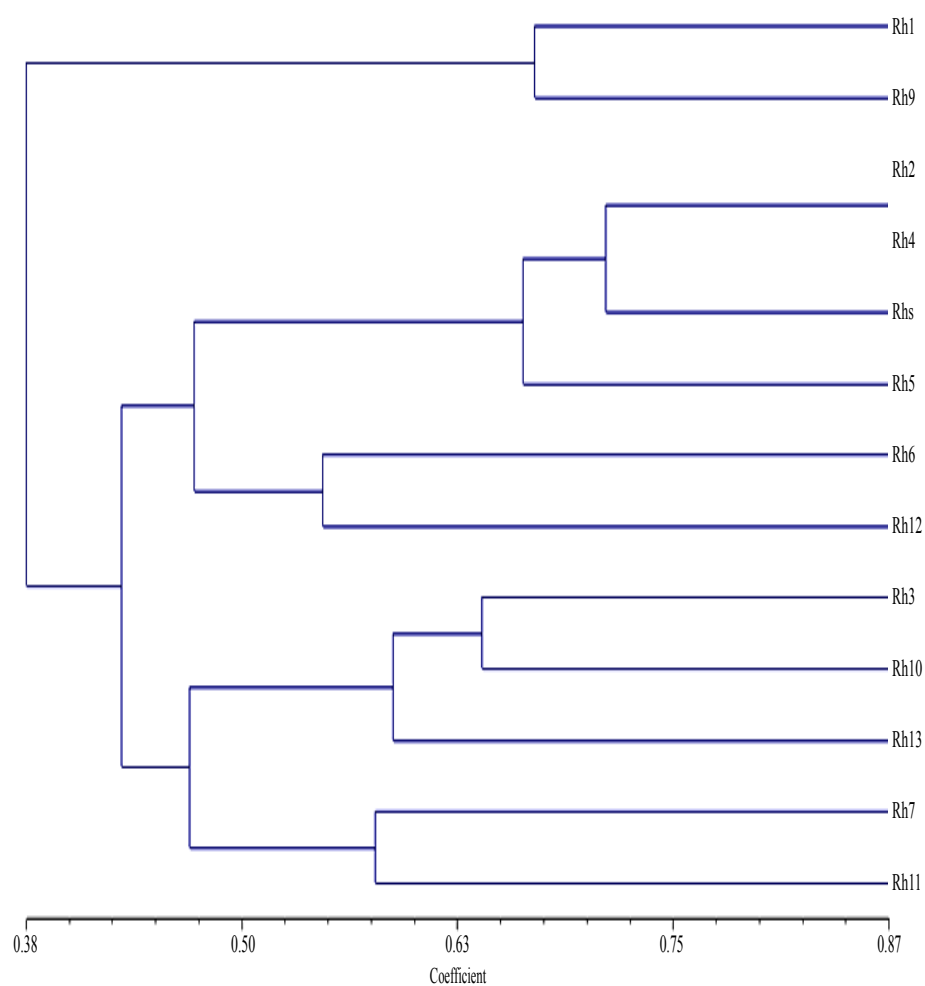

Figure 2: Phylogenetic relationship between 13 isolates using UPGMA method based on antibiotics resistant analyses. 
Citation: Hewedy OA, Eissa RA, Elzanaty AM, Nagaty HH, Abd Elbary MI (2014) Phenotypic and Genotypic Diversity of Rhizobia Nodulating Faba Bean from Various Egyptian Locations. J Bioprocess Biotech 4: 170 doi: 10.4172/2155-9821.1000170

Page 5 of 8

and isolate No.11. Whereas isolates No. Rh11, Rh13 and Rh3 showed $50 \%$ resistance to the tested antibiotics as shown in Table 3, The same Table 3 and Figure 1 showed the wide range of variations among the isolates for its resistant to these discs. These results were similar to those reported by [20].

Salt tolerance: These strains were first screened to examine their resistance to environmental stresses e.g. salt tolerance. The majority of the tested strains were sensitive to salt stress . All 13 rhizobial isolates tolerated $3 \% \mathrm{NaCl}$. Whereas only five isolates are able to grow at $5 \%$ $\mathrm{NaCl}$. only 5 isolates still grew, but 8 isolates failed to grow at the same concentration (Rh1, Rh2, Rh3, Rh5, Rh6, Rh7, Rh8 and Rh11) and showed great inhibition. In fact,Ismailia isolate showed the most salt tolerancy (Figures 2 and 3).

Results in Table 5 showed that all of the 13 isolates were able to survive in salt concentrations ranging between $0.1 \%$ till $3.0 \% \mathrm{NaCl}$
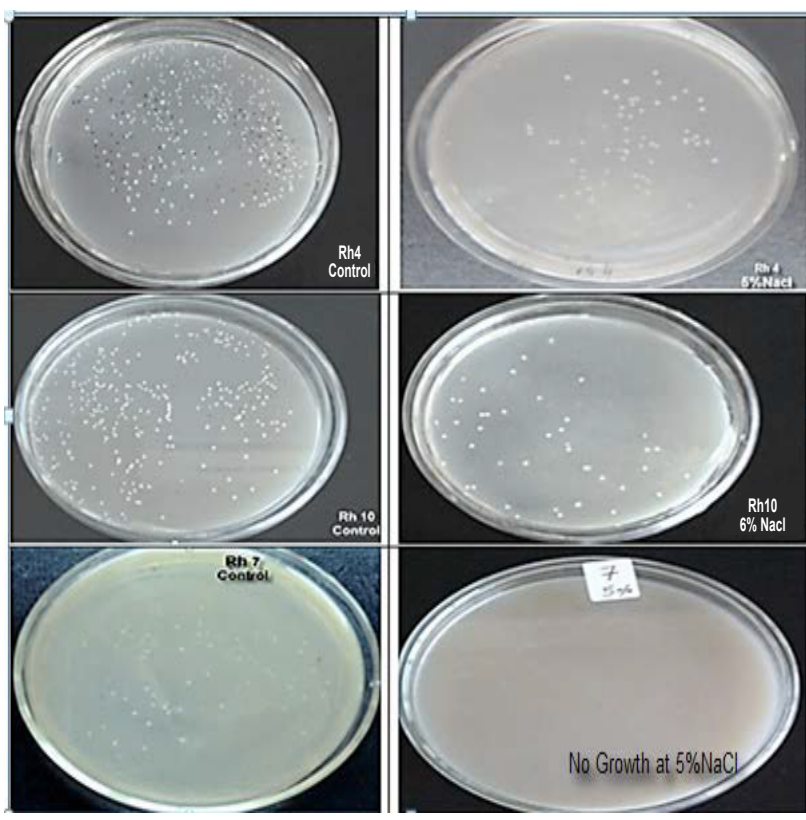

Figure 3: Some isolates growing on YEMA media supplemented with $\mathrm{NaCl}$ as a control and $5 \% \mathrm{NaCl}$ concentration. and a few of them tolerated and survived at $5 \% \mathrm{NaCl}$. These tolerated isolates were isolate No.4 from Zefta City, Ghrbia Governorate ,isolate No.9 from Rafah City, North Sinai Governorate, isolate No.10 from ElMenia Governorate, isolate No.12 from Cairo City, Cairo Governorate and finally isolate No.13 from Ismailia City, Ismailia Governorate. These results were similar to those reported by [21] who found that the Faba bean-nodulating strains EFBRI 35, 41, 92 and 93 that we isolated were salt tolerant, and grew well in $1 \% \mathrm{NaCl}$, and a large number of strains that we later identified as S. meliloti and isolated from Faba bean nodules were resistant to $3 \% \mathrm{NaCl}$. Similar results were reported by who noted that strains belonging to this species are salt tolerant.

The O.D. of all isolates was affected significantly by salt concentration (Figure 4 and Table 6). O.D. decreased with increasing salinity above $1 \%$ concentration. Most isolates had maximum O.D. At $1 \% \mathrm{NaCl}$; all isolates continued to grow strongly at $3 \% \mathrm{NaCl}$, whereas growth of all isolates was inhibited $5 \% \mathrm{NaCl}$ except for isolate No.4, 9, 10, 12 and 13. As a result, the salt tolerance of rhizobia is critical for symbiosis in that it facilitates the survival and growth of rhizobial strains in saline conditions and, in particular, is one of the key mechanisms to enhance the symbiosis under saline conditions [22]. The Ismailia strain was able to tolerate the maximum concentration tested at $5 \% \mathrm{NaCl}$, while without $\mathrm{NaCl}$ we noticed heavy growth of $\mathrm{Rh} .7$ (control), whereas plate No.7 at $5 \% \mathrm{NaCl}$ showed no bacterial growth at all. Therefore this isolate is very sensitive to $\mathrm{NaCl}$ at used concentration.

Data in Table 6 showed that the isolate No. RL9 was the superior strain for salt tolerance The following strains for salt tolerance were the isolates RL12, RL4, RL10 and RL13 The higher growth rate of the Rhizobium isolates may be considered as an indicator of salt tolerance and subsequently, could be considered as an estimate parameter for high nodulation under the saline soil.

\section{Genetic diversity of Faba bean (Rlv) rhizobia using different molecular approaches}

RAPD PCR: Several investigators have studied the genetic diversity of Rlv isolated from several countries around the world [23-26].

RAPD profiles were used to show the genetic polymorphism among isolates of Rhizobium leguminosarum $b v$. Viciae and to discriminate their genetic differences [26]. The genetic diversity of Rhizobium isolated from several countries around the world was studied by [21]. The genetic diversity of thirteen studied strains were

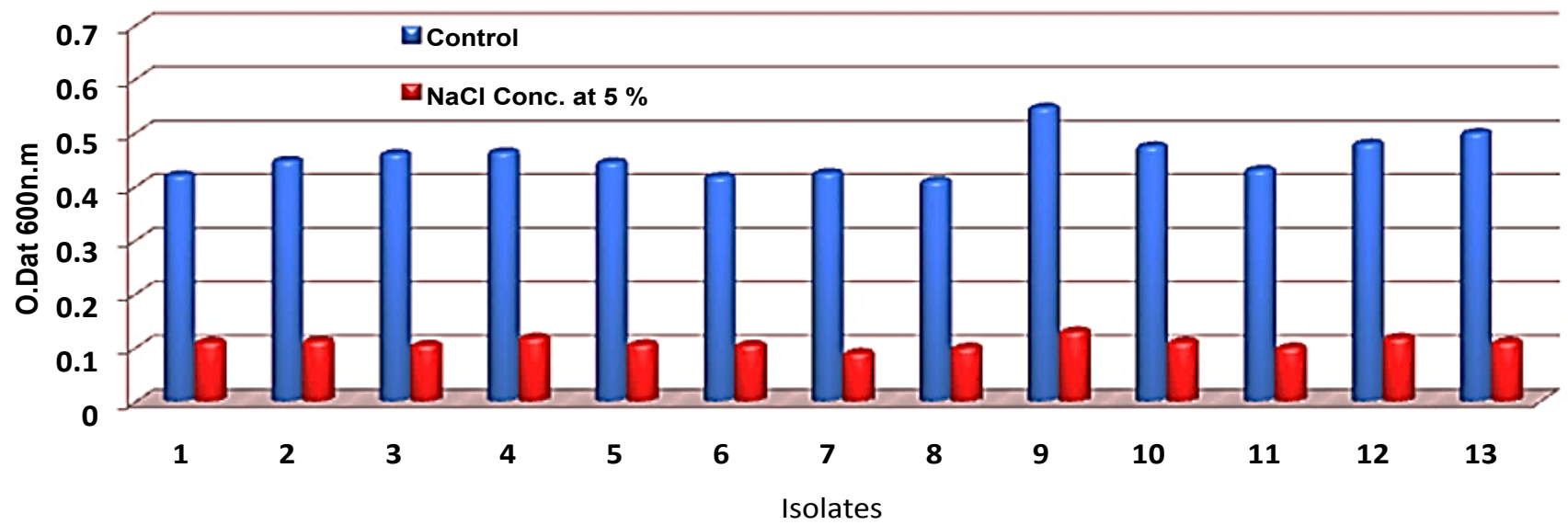

Figure 4: $\mathrm{OD}$ of all isolates at High Concentrations of $\mathrm{NaCl}(5 \%)$ after $72(\mathrm{hr})$ from inoculation. 


\begin{tabular}{|c|c|c|c|c|c|c|c|c|c|c|c|c|c|}
\hline \multicolumn{14}{|c|}{ Isolates } \\
\hline Conc. (\%) & RL 1 & RL 2 & RL 3 & RL 4 & RL 5 & RL 6 & RL 7 & RL 8 & RL 9 & RL 10 & RL 11 & RL 12 & RL 13 \\
\hline 0.1 & $0.421^{a}$ & $0.448^{a}$ & $0.461^{\mathrm{a}}$ & $0.464^{a}$ & $0.445^{\mathrm{a}}$ & $0.418^{a}$ & $0.425^{\mathrm{a}}$ & $0.410^{\mathrm{a}}$ & $0.547^{\mathrm{a}}$ & $0.475^{\mathrm{a}}$ & $0.431^{a}$ & $0.480^{\mathrm{a}}$ & $0.500^{\mathrm{a}}$ \\
\hline 1 & $0.256^{\mathrm{b}}$ & $0.361^{b}$ & $0.256^{b}$ & $0.253^{b}$ & $0.321^{b}$ & $0.258^{\mathrm{b}}$ & $0.321^{b}$ & $0.321^{b}$ & $0.265^{b}$ & $0.248^{b}$ & $0.361^{b}$ & $0.321^{\mathrm{b}}$ & $0.266^{b}$ \\
\hline 3 & $0.150^{\circ}$ & $0.160^{c}$ & $0.140^{c}$ & $0.155^{\mathrm{c}}$ & $0.172^{\mathrm{c}}$ & $0.150^{c}$ & $0.172^{\mathrm{c}}$ & $0.172^{\mathrm{c}}$ & $0.18^{\mathrm{bc}}$ & $0.145^{b}$ & $0.160^{\mathrm{b}}$ & $0.150^{c}$ & $0.152^{c}$ \\
\hline 5 & $0.110^{c}$ & $0.112^{c}$ & $0.105^{c}$ & $0.118^{c}$ & $0.106^{c}$ & $0.105^{c}$ & $0.090^{c}$ & $0.100^{\circ}$ & $0.130^{c}$ & $0.110^{c}$ & $0.100^{\mathrm{b}}$ & $0.118^{c}$ & $0.108^{c}$ \\
\hline
\end{tabular}

$a, b, c=$ values of each trait within each column don't have the same letter are significantly different

Table 6: Effect of different concentrations of $\mathrm{NaCl}$ on Growthafter $72 \mathrm{hr}$. (measuredas optical density) of isolates.

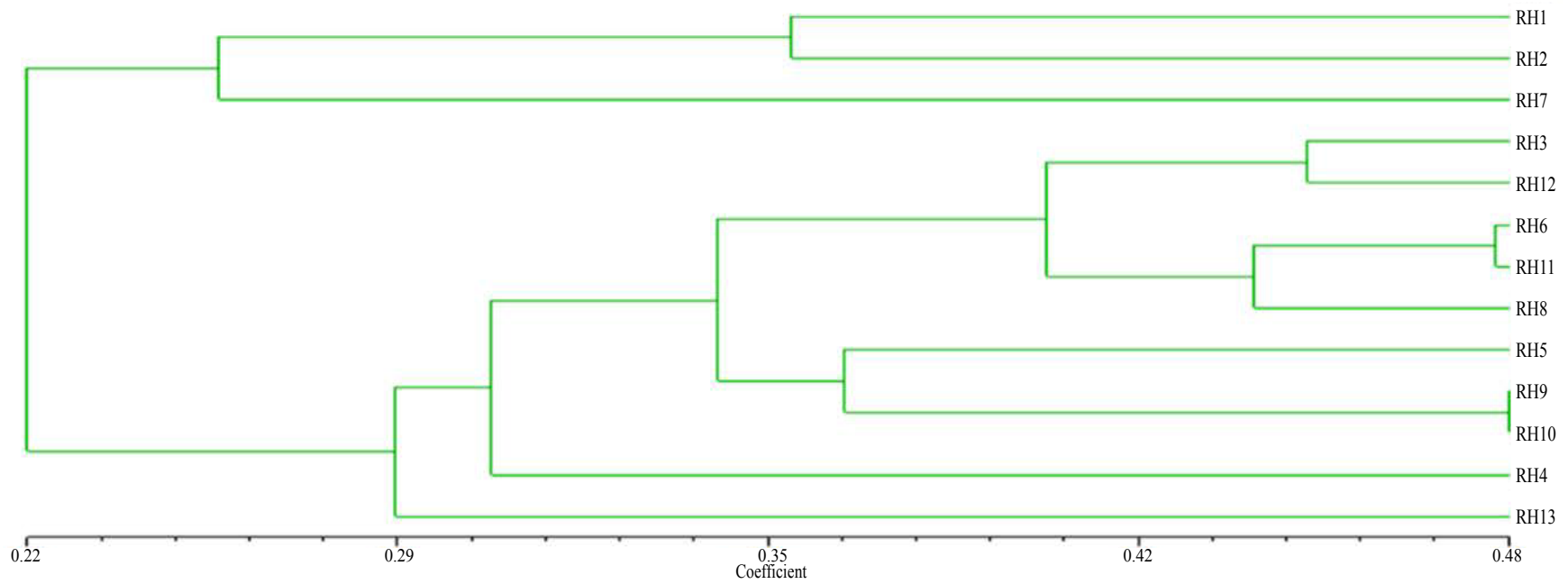

Figure 5: Phylogenetic relationship between 13 Rhizobial isolates using UPGMA method based on RAPD analyses.

examined: Rh1,Rh2, Rh3 , Rh4 , Rh5 , Rh6, Rh7 , Rh8 , Rh9, Rh10, Rh11, Rh12 and Rh13 using six random primers (OPE 15, OPA 04, OPC 06, OPE 20, OPJ 20 and OPG 04), and were used to screen for the polymorphism between the tested isolates. The results of RAPD analysis showed that all used primers were polymorphic. OPE 15 and OPG 04 primers showed the highest polymorphism level among the tested isolates, while OPJ 20 and OPC 06 primers showed the lowest polymorphism level Figure 6.

The similarity matrix values were converted into Dendrogram using UPGMA (Unweight Pair Group Method with the Arithmetic average) clustering method. Cluster analysis divided into two main clusters (Figure 5). The first cluster included isolates from Quesna, Benha, and South Sinai; whereas the second cluster included isolates from Sadat, Cairo, Sues, South Sinai , Beni Suef, Al- Dakahlia , North Sinai, El-Menia, Zefta, and Ismailia. Remarkably, the first cluster was divided into three groups for the isolates were highly related to each other. The second cluster presented ten isolates, the isolates within each group were overlapped, principal coordinates analysis showed similar pattern as cluster analysis. The analysis was based on the number of markers that were similar between any given pair of isolates Table 7 .

All Rhizobia isolates genotypically characterized by RAPD_PCR. Total genomic DNA amplified with six oligonucleotide primers, amplification patterns revealed a high level of polymorphism. All primers produced multiple DNA products ranging in size from 0.2 to $1.5 \mathrm{~Kb}$. Primer OPJ20 Produced multiple DNA products ranging in number from one in isolates $\mathrm{Rh} 11$ and $\mathrm{Rh} 12$ to three bands in $\mathrm{Rh} 1$, Rh 3, Rh 4, Rh 5, Rh 6, Rh 8, Rh 10 and Rh 11. Whereas only Rh 2, Rh
7 and Rh 13 produced two bands. Primer OPE15 Produced multiple DNA products ranging in number from TWO bands in isolate $\mathrm{Rh} 5$ to five bands in isolates Rh 3 and $\mathrm{Rh} 13$. Whereas isolates $\mathrm{Rh} 4, \mathrm{Rh} 8$, $\mathrm{Rh} 10$, Rh 11 and Rh 12 produced four bands . Also isolates Rh 1, Rh 2, $\mathrm{Rh} 6, \mathrm{Rh} 7$ and Rh 9 produced three bands. OPC 06 Produced multiple DNA products ranging in number from two bands in isolates $\mathrm{Rh} 4, \mathrm{Rh}$ 10 , Rh 12 and Rh 13 to four bands in isolates Rh $1, \mathrm{Rh} 3$ and $\mathrm{Rh} 6$. On the other hand isolates $\mathrm{Rh} 2, \mathrm{Rh} 5, \mathrm{Rh} 7, \mathrm{Rh} 8, \mathrm{Rh} 9$ and Rh 11 . OPG 04 Produced multiple DNA products ranging in number from three bands in isolates Rh 2, Rh 3, Rh 5, Rh 6 and Rh 8 to five bands in isolates $\mathrm{Rh} 7, \mathrm{Rh} 11$ and Rh12. Whereas isolates Rh $1, \mathrm{Rh} 4$, Rh 9 , Rh10 and $\mathrm{Rh} 13$ showed four bands. OPA 04 Produced multiple DNA products ranging in number from three bands in isolates $\mathrm{Rh} 2, \mathrm{Rh} \mathrm{3,} \mathrm{Rh} 7$ and $\mathrm{Rh} 11$ to six in isolates Rh9. Also five bands in isolates $\mathrm{Rh} 4$ and $\mathrm{Rh} 10$ were produced, further to isolates $\mathrm{Rh} 1, \mathrm{Rh} 5, \mathrm{Rh} 6, \mathrm{Rh} 8, \mathrm{Rh} 12$ and $\mathrm{Rh}$ 13 showed four bands. Finally primer OPE 20 produced multiple DNA products ranging in number from two bands in only isolate $\mathrm{Rh} 2$ to five bands in several isolates $\mathrm{Rh} 10, \mathrm{Rh} 12$ and $\mathrm{Rh} 13$. Also the same primer produced four bands in isolates $\mathrm{Rh} 1, \mathrm{Rh} 3, \mathrm{Rh} 7$ and $\mathrm{Rh} 9$. Whereas isolates Rh 4, Rh 5, Rh 6, Rh 8 and Rh 11 showed only three bands. All six primers were successfully generated reproducible polymorphic bands to evaluate the degree of genetic diversity and calculating the genetic distances of Rhizobia based on the DNA nucleotide sequence using RAPD and used to identify the genetic variability and genetic relationship among the thirteen genotypes. Also we used Sequence analysis of $16 \mathrm{~S} \mathrm{rDNA}$ and subsequent BlastN analyses indicated that the majority of isolated strains were Rlv. [27].

To further confirm the taxonomic status of the Faba bean 
Citation: Hewedy OA, Eissa RA, Elzanaty AM, Nagaty HH, Abd Elbary MI (2014) Phenotypic and Genotypic Diversity of Rhizobia Nodulating Faba Bean from Various Egyptian Locations. J Bioprocess Biotech 4: 170 doi: 10.4172/2155-9821.1000170

Page 7 of 8

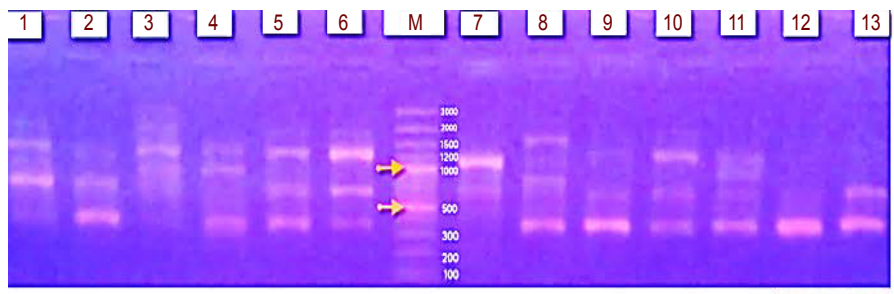

OPJ 20

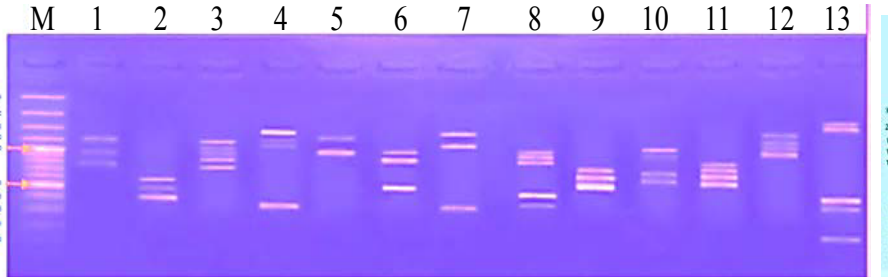

OPE 15

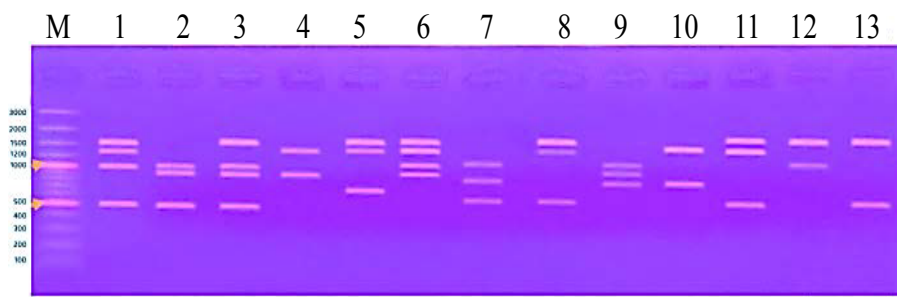

OPE 16
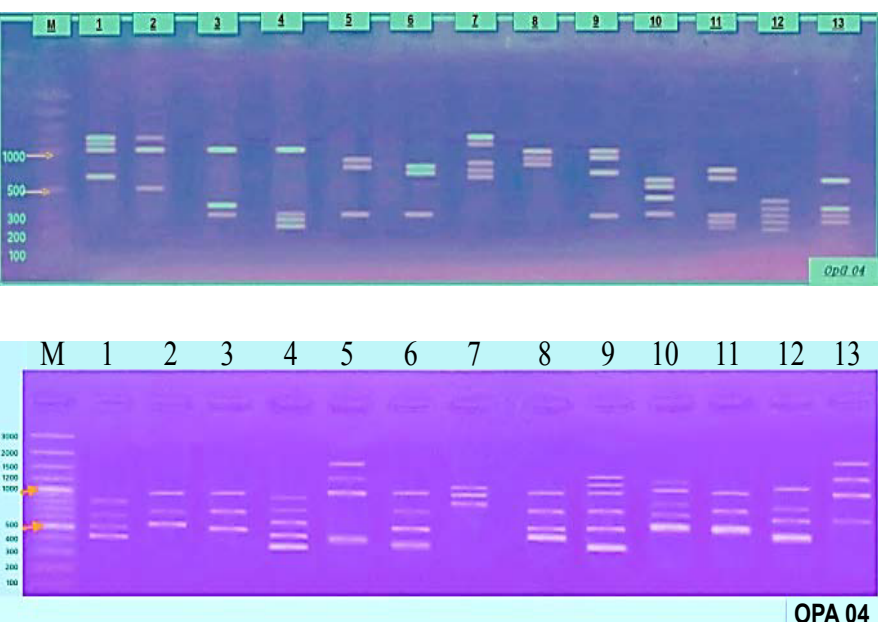

OPA 04

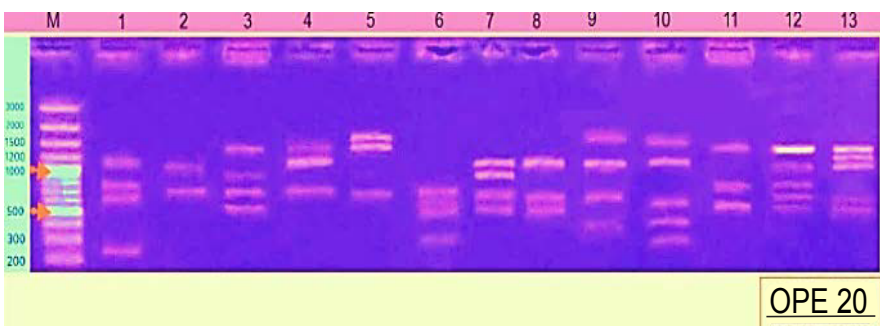

Figure 6: $1 \%$ Agarose gel electrophoresis of RAPD PCR products. (M) DNA size marker (Gene Ruler ${ }^{\text {TM }}$ 100bp Plus DNA Ladder, Fermentas); 1=Rh. Quesna; 2=Rh. Banha; 3=Rh. Sadat ; 4=Rh. Zefta ; 5=Rh. Baneswaif; 6=Rh. Sues; 7=Rh. South Sina; 8=Rh. Al Arish; 9=Rh. Rafah; 10=Rh. New El-Menia; 11=Rh. Moshtohor; 12=Rh. Cairo and 13=Rh. Ismailia.

\begin{tabular}{|c|c|c|c|c|c|c|c|c|c|c|c|c|c|}
\hline Isolates & Rh 1 & Rh 2 & Rh 3 & Rh 4 & Rh 5 & Rh 6 & Rh 7 & Rh 8 & Rh 9 & Rh 10 & Rh 11 & Rh 12 & Rh 13 \\
\hline Rh 1 & 1 & & & & & & & & & & & & \\
\hline Rh 2 & 0.35 & 1 & & & & & & & & & & & \\
\hline Rh 3 & 0.34 & 0.27 & 1 & & & & & & & & & & \\
\hline Rh 4 & 0.31 & 0.16 & 0.32 & 1 & & & & & & & & & \\
\hline Rh 5 & 0.17 & 0.06 & 0.25 & 0.26 & 1 & & & & & & & & \\
\hline Rh 6 & 0.23 & 0.16 & 0.36 & 0.29 & 0.35 & 1 & & & & & & & \\
\hline Rh 7 & 0.31 & 0.2 & 0.28 & 0.25 & 0.22 & 0.21 & 1 & & & & & & \\
\hline Rh 8 & 0.34 & 0.19 & 0.35 & 0.36 & 0.39 & 0.41 & 0.32 & 1 & & & & & \\
\hline Rh 9 & 0.15 & 0.3 & 0.29 & 0.3 & 0.36 & 0.38 & 0.22 & 0.25 & 1 & & & & \\
\hline Rh 10 & 0.18 & 0.21 & 0.33 & 0.22 & 0.36 & 0.38 & 0.13 & 0.29 & 0.48 & 1 & & & \\
\hline Rh1 1 & 0.2 & 0.2 & 0.36 & 0.29 & 0.35 & 0.48 & 0.25 & 0.46 & 0.38 & 0.48 & 1 & & \\
\hline Rh 12 & 0.22 & 0.15 & 0.44 & 0.36 & 0.34 & 0.41 & 0.28 & 0.44 & 0.25 & 0.37 & 0.46 & 1 & \\
\hline Rh 13 & 0.15 & 0.18 & 0.26 & 0.27 & 0.29 & 0.2 & 0.23 & 0.3 & 0.21 & 0.25 & 0.35 & 0.43 & 1 \\
\hline
\end{tabular}

Table 7: Similarity between different tested isolates.

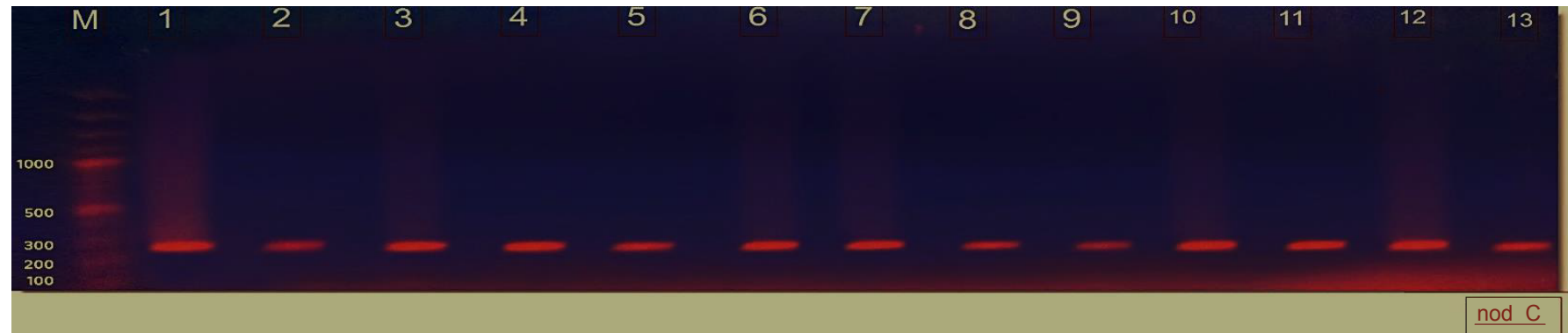

Figure 7: Identification of Rhizobial isolates by amplifying a specific region of nodC gene (220 bp) 
Citation: Hewedy OA, Eissa RA, Elzanaty AM, Nagaty HH, Abd Elbary MI (2014) Phenotypic and Genotypic Diversity of Rhizobia Nodulating Faba Bean from Various Egyptian Locations. J Bioprocess Biotech 4: 170 doi: 10.4172/2155-9821.1000170

nodulating Rlv strains, and to examine variation in a plasmid-borne, symbiotic specific gene, primers nodCf and nodCR were designed to amplify a region of the nodC specific for $R l v$. as well as the nodC gene amplification results (Figure 7). PCR analyses done in this study showed that all of the strains that were identified as Rlv produced about a 220 bp DNA fragment using a nodC-specific primer pair.

\section{Conclusions}

Salt-stress are the major constraints to plant productivity and isolation of effective rhizobia to inoculate the leguminous crop plants could be an important strategy to improve the efficiency of rhizobiumlegume symbiosis and thereby productivity. In our study we isolated of Faba plants thirteen R. leguminosarum sv. Viciae isolates, identified by phenotypic and genotypic characteristics.

\section{References}

1. Bond DA (1976) Evolution of Crop Plants. Longman and Hall, London, UK

2. Allen ON, Allen AK (1981) Leguminosae: Source Book of Characteristics, Uses and Nodulation. Macmillan, London, UK.

3. Zakhia F, de Lajudie P (2001) Taxonomy of rhizobia. Agronomie 21: 569-576.

4. Stocker R, Seymour JR, Samadani A, Hunt D (2008) Rapid chemotactic response enables marine bacteria to exploit ephemeral microscale nutrient patches. Proc Natl Acad Sci 105: 4209-4214.

5. Amarger N, Bours M, Revoy F, Allard MR, Laguerre G (1994) Rhizobium tropic nodulates field-grown Phaseolus vulgaris in France. Plant Soil 161: 147-156.

6. Moreira FMS, Haukka K, Young JPW (1987) Biodiversity of rhizobia isolated from a wide range of forest legumes in Brazil. Mol Ecol 7: 889-895.

7. Binde DR, Menna P, Bangel EV, Barcellos FG (2009) Rep-PCR fingerprinting and taxonomy based on the sequencing of the 16S rRNA gene of 54 elite commercial rhizobial strains. Appl Microbiol Biotechnol 83: 897-908.

8. Singleton PW, Bohlool BB (1984) Effect of salinity on nodule formation by soybean. Plant Physiol 74: 72-76.

9. Laguerre G, Nour SM, Macheret V, Sanjuan J, Drouinb P, et al., (2001) Classification of rhizobia based on nod $\mathrm{C}$ and nif $\mathrm{H}$ gene analysis reveals close phylogenetic relationship among Phaseolus vulgaris symbionts. Microbiol 147: 981-993.

10. Williams JGK, Kubelik AR, Livak KJ, Raifalski A, Tingey SV (1990) DNA polymorphisms amplified by arbitrary primers are useful as genetic markers. Nucleic Acids Res 18: 6531-6535

11. Labes G, Ulrich A, Lentzsch P (1996) Influence of bovine slurry deposition on the structure of nodulating Rhizobium leguminosarum bv. Vicia soil populations in a natural habitat. Appl Environ Microbiol 62: 1717-1722.

12. Oliveira IAD, Vasconcellos MJ, Seldin L, Paiva E, Vargas MA, et al., (2000) Random Amplified Polymorphic DNA Analysis of effective Rhizobium sp. Associated with Beans cultivated in Brazilian Cerrado Soils. Braz J Microbio 31: $39-44$
13. Eaglesham AR (1987) The use of intrinsic antibiotic resistance for Rhizobium study. In: Elkan, H. (Ed.), Symbiotic Nitrogen Fixation Technology. Marce Dekker, NY, USA.

14. Moschetti G, Peluso A, Protopapa A, Anastasio M, Pepe Q, et al., (2005) Use of nodulation pattern, stress tolerance, nodC gene amplification, RAPDPCR and RFLP-16S rDNA analysis to discriminate genotypes of Rhizobium leguminosarum symbiovar viciae. Sys \& App Microbiol 28: 619-631.

15. Hahn NJ (1964) The Congo red reaction in bacteria and its usefulness in the identification of Rhizobia. Can J Microbiol 12: 725 - 733.

16. Laguerre G, Allard MR, Revoy F, Amarger N (1994) Rapid identification of rhizobia by restriction fragment genes. Appl Environ Microbiol 60: 56-63.

17. Navarro DN, Buendiab AM, Camachoa M, Lucasc MM, Santamaria C (2000) Characterization of Rhizobium spp. bean isolates from South-West Spain. Soil Biol Biochem 32: 1601-1613.

18. Hafeez FY, Asad S, Ahmad T, Malik KA (1995) Host specificity and characterization of fast-growing rhizobia from Macroptilium atropurpureum $\mathrm{cV}$. Siratro in Pakistan. Soil Biol Biochem 27: 729-733.

19. Hagedorn C (1979) Relationship of antibiotic resistance to effectiveness in Rhizobium trifolii populations. Soil Sci Soc Am J 43: 921-925.

20. Rashid MD, Sattar A, Uddin MDI, Young JPW (2009) Molecular characterization of symbiotic root nodulating rhizobia isolated from lentil. EJEAF Che 8: 602-612.

21. Shamseldin A, El-Saadani M, Sadowsky MJ, An CS (2009) Rapid identification and discrimination among Egyptian genotypes of Rhizobium leguminosarum sv. viciae and Sinorhizobium meliloti nodulating Faba bean (Vicia faba L.) by analysis of nodC, ARDRA, and rDNA sequence analysis. Soil Biology \& Biochemistry 41: 45-53.

22. Cordovilla MP, Ligero F, Lluch C (1999) Effect of salinity on growth, nodulation and nitrogen assimilation in nodules of faba bean (Vicia faba L.). Appl Soil Ecol 11: $1-7$.

23. Amanuel G, Kuhne RF, Tanner DG, Viek PLG (2000) Biological nitrogen fixation in Faba bean (Vicia faba L.) in the Ethiopian highlands as affected by $P$ fertilization and inoculation. Biol \& Fertil Soils 32: 353-359.

24. Mutch LA, Tamimi SM, Young JPW (2003) Genotypic characterization of rhizobia nodulating Vicia faba from soils of Jordan: a comparison with UK isolates. Soil Biol \& Bioch 35: 709-714.

25. Mutch LA, Young PW (2004) Diversity and specificity of Rhizobium leguminosarum symbiovar viciae on wild and cultivated legumes. Molecular Ecology 13: 2435-2444.

26. Ventorino V, Chiurazzi M, Aponte M, Pepe O, Moschetti G (2007) Genetic diversity of a natural population of Rhizobium leguminosarum sv. Vicia nodulating plants of Vicia faba in the Vesuvian area. Current Microbiology 55 512-517.

27. Ismail M, El-Zanatay AM, Eissa RA, Hewedy OA (2013) Genetic Diversity of Rhizobium leguminosarum as Revealed by $16 \mathrm{~S}$ rRNA Gene Sequence. American-Eur J Agric \& Environ Sci 13: 797-801 